\title{
BackChat
}

\section{My life with Asperger's syndrome}

$M$ y name is Mark Whitenstall. I am 9 years old and I have Asperger's syndrome. This means that I have trouble with social skills and communication. Because I have a Statement (SSEN) I go to special classes at school with my support teacher who helps me with my conversation skills and my handwriting. I am not very good at some things in PE either and get help with this as well and am monitored during break times. However I am quite good at learning other things like spelling. I love to read all kinds of information books and fiction andIcanwrite good stories for my class work.

There are other children in my school who have different disorders than mine but we are all quite similar when it comes to learning because we all find some things hard to do.

When I go out to play with my friends I have trouble knowing what is the right thing to do or say and it's the same at school.

I am sometimes bullied at school and by others outside of school. They call me names and take advantage of me because I think having Asperger's syndrome makes me an easy target for bullies.
When I am getting washed in the mornings (which is also hard to do) I have sensitivities to water temperature (i.e. I think tepid water is hot). I also find that when other people touch me I can experience big amounts of pain (i.e. like going to the hairdressers and getting my nails cut).

I get lots of headaches which I think is because I have to think things through more than other people.

I always have to get things right first time or it usually annoys me.

When I am out shopping with my family or am playing out I don't always recognise where I am and can get lost easily-I recently went down one aisle in the shop to get my comic and came back up a different aisle and couldn't find my mum.

My parents give me supplements every day called Eye Q which we think helps me with my eye and brain function. I used to take Effalex but then we heard that Eye Q was better and changed to this one.

I would like doctors to research more into autism and especially Asperger's syndrome and learning difficulties in general because there are so many people who have these problems which affect your life a lot. It is also important to get help in school.
I hope you find this helpful and can do more to help people with Asperger's syndrome.

This is a poem I wrote for a school project:

\section{Blizzard}

I struggle to set up camp on the mountainous ground,

but the blizzard destroys everything for miles around.

When I got inside the tent I heard piercing screams,

the screams of those who came with no rights or means.

Yeti are the only things for miles around,

no one else could live on higher ground.

At the top there are bones of those who got lost,

killed in the blizzards and huge showers of frost.

Newcastle upon Tyne, UK

Correspondence to: Dr H Marcovitch, Syndication Editor, BMJ Publications; h.marcovitch@btinternet.com

\section{The playground (on a "normal" day)}

I stand alone in the playground... Looking.

Looking, at all the people

Laughing and poking fun, and usually a

punch or two,

It's "normal".

One of them walks past me...

Staring.

Staring, as if I'm from another planet,

"Three pounds fifty at Harry's on a night get an 'air cot",

It's "normal".

My friend comes, says hi...

Talking.

Talking, though we already know the

conversation

Same old rubbishy jokes, same clichéd

words exchanged.

It's "normal".
The rusty old bell rings...

Droning.

Droning, as if we can't hear it

Of to the same stinky lessons we have past heard of,

It's "normal".

What's normal?...

Normal.

Free from any mental illness; sane,

Relating to or characterised by average

intelligence or development,

Fitting in with everyone else.

Do you really want to be the same as everyone else?

I mean... why?

You be you and I'll be me.

Why not just break the rules for a change?

I don't want to be anyone else! 